\title{
REVIEWS
}

\section{Antilipolysis as a Tool in the Study of Clinical and Experimental Diabetes*}

\section{Lecture for the 1968 Minkowski Award}

\author{
Lars A. Carlson \\ King Gustaf Vth Research Institute, Stockholm and Department of Geriatrics, Uppsala University, Uppsala, \\ Sweden
}

Received : June 20, 1969

In December 28, 1875, Bürstenmacher LodwıG FreckMaNN, who was 58 years old, was brought into the Göttingen hospital. He was suffering from diabetes mellitus. In spite of various kinds of treatment, his urinary sugar varied between 50 and $200 \mathrm{~g}$ and the urine volume between 2 and 41 per day until February 1876. Then Wrihelm EbsteIr, at that time professor of medicine at Göttingen, started to treat Bürstenmacher Freckmand with $5 \mathrm{~g}$ of sodium salicylate per day. Within a few days the urine was sugar-free. The patient continued to take $5 \mathrm{~g}$ a day, and at follow up in May 1876 there was no sugar demonstrable by Fehling's Lösung in the urine and he had increased in weight from 151 to 169 Pf [12].

I wanted to begin this lecture with a summary of this interesting case because Bürstenmacher FrEckMATN is probably the first reported case treated with an antilipolytic agent. I shall later come back and demonstrate that salicylates are antilipolytio compounds.

\section{What is lipolysis in adipose tissue?}

Lipolysis in adipose tissue is the process by which the stored triglycerides (TG) are hydrolyzed to yield fatty acids and glycerol. The lipolytic process is schematically depicted in Fig. 1. The result of lipolysis is mobilization of the fatty acids and the glycerol liberated by the hydrolysis. The fatty acids enter the blood and are immediately bound to albumin. They are then known as free fatty acids (FFA). Lipolysis is thus one fundamental process controlling mobilization of FFA. Another important process in this regard is the reesterification process (Fig. 1). This is, however, beyond the scope of this lecture.

\section{Regulation of lipolysis in adipose tissue}

Fig. 1 summarizes present concepts, as they are derived from studies mainly on rat epididymal fat, on the regulation of lipolysis. The key role played by 3,5-cyclic AMP in activating inactive lipase into active lipase and thereby stimulating lipolysis is evident.

* Supported by grants from the Swedish Medical Research Foundation (19x-204).

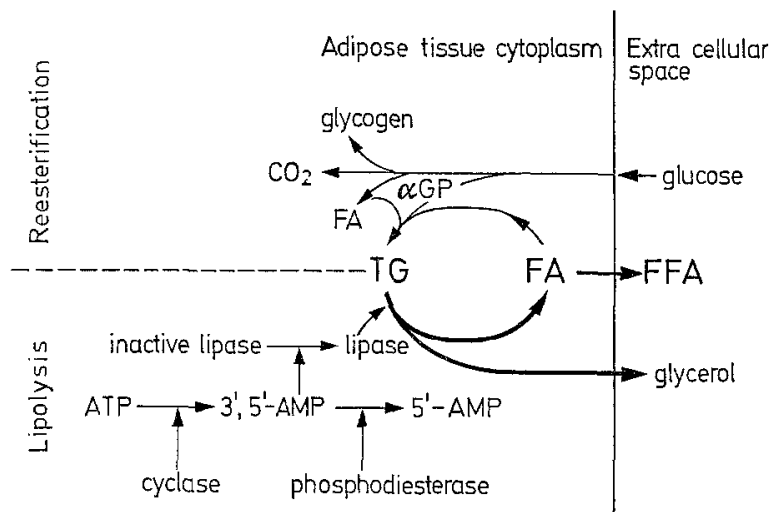

Fig. 1. Schematic figure illustrating the two basic mecha. nisms - lipolysis and re-esterification - influencing the mobilization of fatty acids (FA) from adipose tissue. The triglycerides (TG) are hydrolyzed by lipases to yield FA and glycerol. All glycerol is released from the tissue and cannot be utilized for synthesis of new TG. For this purpose $\alpha$-glycerophosphate $(\alpha-G P)$, derived from glucose, is obligatory. A postulated key role of cyclic AMP $\left(3^{\prime}, 5^{\prime}\right.$ AMP) is indicated. Cyclic AMP is believed to activate the lipolytic activity. It is also shown how the level of cyclic AMP is controlled by the cyclase and the phosphodiesterase systems - evidently key regulators of lipolysis in adipose tissue

Table 1. Some compounds affecting lipolysis of adipose tissue triglycerides

\begin{tabular}{|c|c|}
\hline Stimulation & Inhibition \\
\hline Catecholamines ${ }^{\mathrm{a}}$ & Insulin ${ }^{\mathrm{a}}$ \\
\hline $\mathrm{ACTH}$ & Prostaglandinsa \\
\hline Growth hormone & Oxytocin \\
\hline TSH & Vasopressin \\
\hline Glucagon $\mathrm{b}$ & Metabolitesa, c \\
\hline Secretin & Nicotinic acida \\
\hline 'Thyroxine a & Salicylates \\
\hline Cortisone & Pyrazoles \\
\hline Methylxanthinesa & Sympathetic blocking agenta \\
\hline
\end{tabular}

A number of compounds, several of them occurring physiologically, have an influence on lipolysis in adipose tissue (Table 1). It is of special interest in connection with diabetes that insulin is a most potent antilipolytic agent. 


\section{Physiologic role of $F F A$ mobilization}

The physiologic role of FFA mobilization is to supply the various tissues of the body, except the central nervous system, with energy substrate as shown in Table 2.

\section{Metabolism of FFA}

The albumin-bound FFA are utilized by most tissues, except the nervous tissues, to yield energy and carbon dioxide as shown in Fig. 2. When FFA have been taken up into a tissue they are immediately esteri-

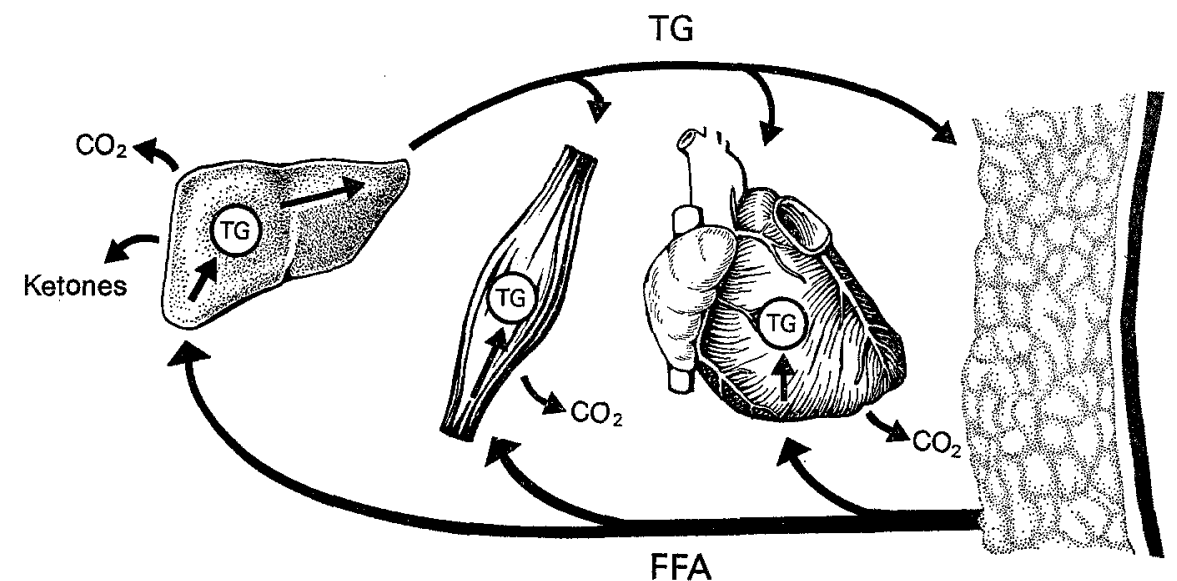

Fig. 2. The lipolytic process in adipose tissue liberates fatty acids, which are mobilized into the blood where they are bound to albumin and transported as free fatty acids (FFA). FFA are taken up by various tissues, immediately esterified to TG. The fatty acids may then be stored, or oxidized to generate energy and $\mathrm{CO}_{2}$. In the liver they may also be resecreted into plasma as lipoprotein-TG, or oxidized to yield ketone bodies. $\mathrm{TG}=$ plasma or tissue triglycerides

Table 2. Role of lipolysis in adipose tissue in the caloric homeostasis in man under normal conditions

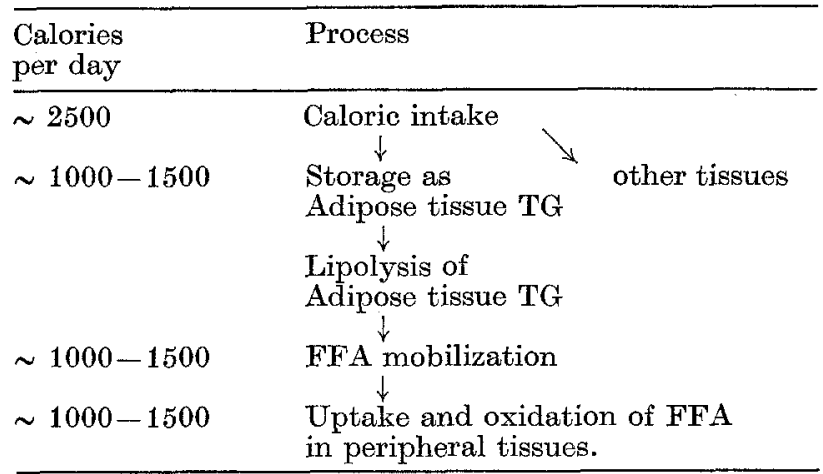

$\overline{\mathrm{TG}}=$ triglycerides. $\quad \mathrm{FFA}=$ free fatty acids.

Table 3. Effect of nicotinic acid on the splanchnic producduction of $\beta$-hydroxybutyrate

\begin{tabular}{|c|c|c|c|c|c|}
\hline \multirow[b]{2}{*}{ Minutes } & \multicolumn{3}{|c|}{$\begin{array}{l}\text { Before nicotinic } \\
\text { acid }\end{array}$} & \multicolumn{2}{|c|}{$\begin{array}{l}\text { After nicotinic } \\
\text { acid }\end{array}$} \\
\hline & $20-40$ & $9-20$ & $0-8$ & $30-40$ & $60-70$ \\
\hline \multirow{2}{*}{$\begin{array}{l}\text { FFA uptake } \\
\beta \text {-HBA } \\
\text { production }\end{array}$} & 0.17 & 0.20 & 0.27 & 0.04 & 0.16 \\
\hline & 0.19 & 0.20 & 0.23 & 0.01 & 0.01 \\
\hline
\end{tabular}

Values in mmole/min. Mean values from 8 subjects [11].

A great part of the caloric intake - fat as well as carbohydrate - is stored for some time in adipose tissue as TG until needed. They are then mobilized as FFA by means of lipolysis. fied, and stored as TG until the fatty acids are split off and oxidized to yield energy. In the liver there are two additional pathways for FFA. They may be incorporated into the TG-fraction that is incorporated into the triglycerides of plasma lipoproteins (very low density lipoproteins). In this way the fatty acids are re-circulated into plasma and may be transported to adipose tissue and other tissues. Furthermore, the fatty acids may be oxidized in the liver to yield ketone bodies (Fig. 2).

There is one feature of the metabolism of FFA that is of special importance for the development of various pathologic conditions. Animal studies have indicated that the uptake of FFA in various tissue is proportional to the amount of FFA perfusing the tissue $[22,13]$. We have demonstrated that the same is true in man for the splanchnic region [11]. This means that it is not a tissue in itself that regulates the uptake of FFA, but rather the rate of mobilization of FFA. Thus antilipolytic agents might be assumed to reduce tissue uptake of FFA.

\section{Excessive mobilization of FFA}

When the mobilization of FFA is excessive in relation to the demands of the energy metabolism, the events depicted in Fig. 3 may occur. Increased tissue levels of $\mathrm{TG}$, hypertriglyceridaemia and ketonaemia are all sequences of excessive IFFA metabolism, and these symptoms are all well known to occur also in diabetes mellitus. In addition to these effects, high 
plasma levels of FFA have also been suggested to cause insulin insensitivity and hyperglycaemia, the so-called RuANDLE effect $[15,21]$.

\section{Mobilization of FFA in diabetes mellitus}

It has been known for several years that plasma FFA levels are elevated in diabetes mellitus $[16,1]$. We could demonstrate that the mobilization of FFA from adipose tissue was enhanced in diabetes mellitus and will only be briefly summarized here. Nicotinic acid lowers fasting levels of FFA in plasma, as well as levels raised by catecholamines in man and in several other species. Nicotinic acid inhibits lipolysis in isolated adipose tissue in vitro, and prevents the usual rise of cyclic-AMP (see Fig. 1) induced by catecholamines in this tissue (2). Afterintravenous administration, nicotinic acid is rapidly taken up by adipose tissue. It appears from these observations that nicotinic acid should be

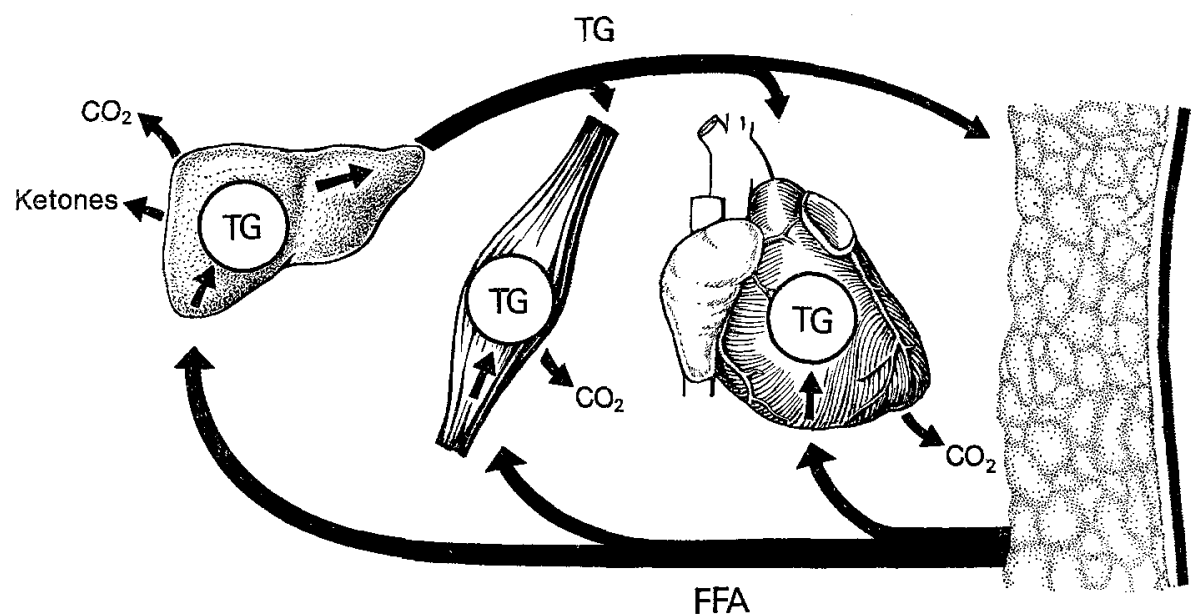

Fig. 3. Excessive mobilization of F'FA. This syndrome is caused by an exaggerated rate of mobilization of FFA and may induce, among other things, increased TG pools in various tissues, including blood and also ketonaemia

[5]. This work was then extended in great detail, by ÖSTMAN [18] confirming increased lipolysis in adipose tissue from patients with juvenile diabetes.

Thus FFA mobilization is increased in diabetes mellitus and many, if not all, of the metabolic derangements of diabetes might be induced by excessive FFA mobilization.

To assess the role of excessive FFA mobilization, caused by increased lipolysis, for metabolic abnormalities in diabetes mellitus such as ketosis, hyperglycaemia, fatty liver, and hypertriglyceridaemia we wanted to use an agent other than insulin with antilipolytic properties.

The observations mentioned in the introduction made us study acetyl-salicylate in this regard. We found that it was indeed an inhibitor of FFA mobilization and of lipolysis in adipose tissue[6]. This compound had several disadvantages, however, it had to be used in high doses and it was a rather weak inhibitor. Instead of applying salicylates in the study of diabetes, we continued to look for other antilipolytic agents. A potent antilipolytic compound was then found in nicotinic acid [10].

\section{Nicotinic acid as antilipolytic agent}

The actions of nicotinic acid on FFA mobilization and on lipolysis have been reviewed elsewhere $[10,3,4]$, an ideal antilipolytic agent. Unfortunately it has, apart from clinical side effects such as flush, some disadvantages. One of these is the rebound phenomenon $[10,19]$, which has to be carefully considered during prolonged treatment with nicotinic acid.

Effect of nicotinic acid on FF $A$ and lipolysis in clinical and experimental diabetes

Nicotinic acid was found to lower plasma FFA levels in diabetic patients [7]. The increased FFA levels [8] and the increased lipolytic rate in adipose tissue [17] seen in alloxan-diabetic rats are also depressed by nicotinic acid. Nicotinic acid completely prevents the increase in plasma FFA levels seen in the acute insulin. deficiency syndrome produced by administration of anti-insulin serum, as shown in Fig. 4 [14].

Effect of nicotinic acid on various metabolic derangements of the acute insulin-deficiency syndrome in rats

Administration of anti-insulin serum to rats rapidly induces a diabetic syndrome with hyperglycaemia [23]. Fig. 4 shows that $6 \mathrm{~h}$ after administration to rats of anti-insulin serum, the concentration of plasma FFA, plasma $\beta$-hydroxybutyrate, plasma TG and liver TG have all increased. Nicotinic acid prevents all these increases (Fig. 4). Thus an antilipolytic agent prevents the occurrence of four of the metabolic derangements seen 
in diabetes. This lends strong support to the hypothesis, depicted in Fig. 3, connecting excessive FFA mobilization with these metabolic abnormalities of diabetes mellitus.
Aspects of antilipolytic agents in the future

Up to the present time, antilipolytic agents such as nicotinic acid have been most useful as experimental tools in the study of various abnormalities in diabetes.

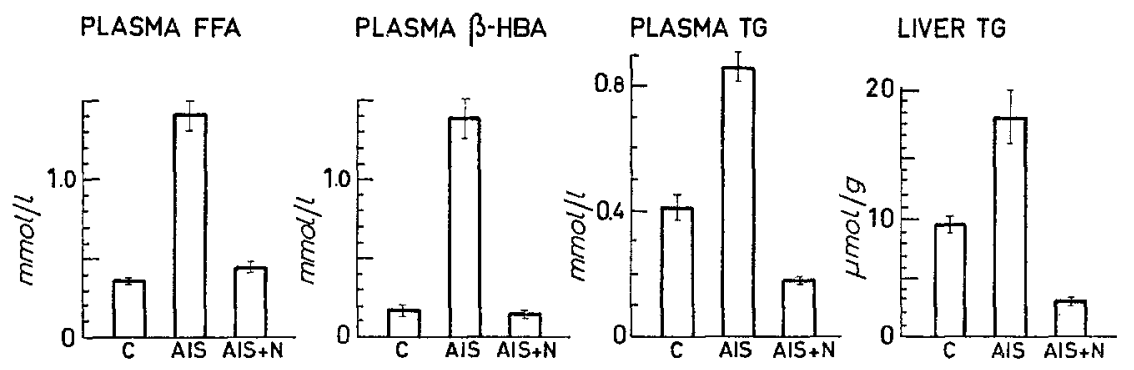

Fig. 4. Summary of results obtained with nicotinic acid (N) on various metabolic abnormalities occurring in rats treated with anti-insulin serum (AIS). From ref (20) $\mathrm{C}=$ controls, $\mathrm{FFA}=$ froe fatty acids, $\beta$-HBA $=\beta$-hydroxybutyric acid, $\mathrm{TG}=$ triglycerides

\section{Effect of nicotinic acid on ketosis in diabetes mellitus}

Administration of nicotinic acid to.normal persons or to patients with diabetes mellitus lowers the plasma levels of $\beta$-hydroxybutyric acid [9]. In Fig. 5 a typical study in a diabetic patient is shown. The temporal relationship between the changes in blood levels of FFA and $\beta$-hydroxybutyrate - first a fall of FFA followed by a decrease in ketones - also strongly suggests that nicotinic acid lowers ketones by reducing FFA mobilization.

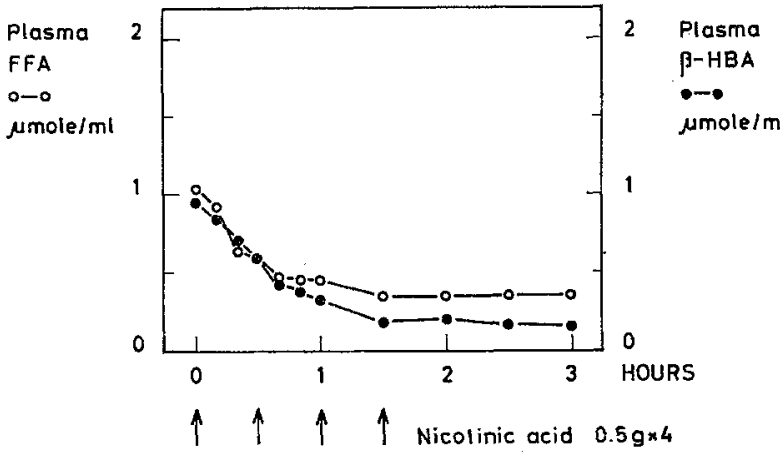

Fig. 5. Effect of repeated $1 / 2 \mathrm{~g}$ doses of nicotinic acid by mouth on plasma levels of FFA and $\beta$-hydroxybutyric acid in an insulin-dependent man. Observe the temporal relationship between FFA and $\beta$-hydroxybutyric acid

It is conceivable that the reduction of the concentration of $\beta$-hydroxybutyrate in plasma may be caused by an increased peripheral utilization of this substrate, due to the reduced availability of the usual substrate, FFA. To study the cause of the reduced ketone levels after administration of nicotinic acid, we measured the splanchnic ketone body production in man [11]. Table 3 summarizes the results. It can be seen that the production of $\beta$-hydroxybutyrate was reduced by 95 per cent by nicotinic acid. This fits well with the hypothesis put forward in Fig. 2 and 3, implying an essential role of FFA mobilization, and thus lipolysis, in controlling ketone body formation.
Good clinical results have, however, been seen in diabetic ketoacidosis [20], but an almost continuous administration is required. This is due to the hyperactive lipolysis occurring when the antilipolytic effect has vanished. This results in overshoot in FFA levels (Fig. 6). This may of course induce all the events occurring in the syndrome of excessive mobilization. Paradoxically, we may thus induce excessive mobilization of FFA with an antilipolytic agent. An example of that is seen

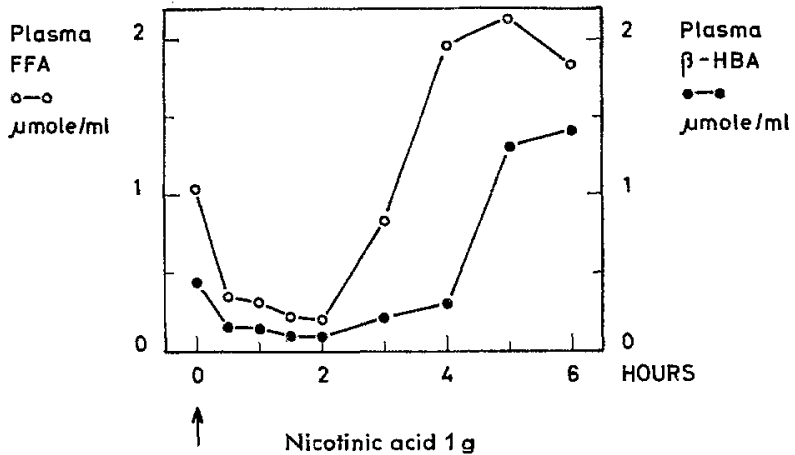

Fig. 6. Effect of $1 \mathrm{~g}$ of nicotinic acid by mouth on plasma levels of FFA and $\beta$-hydroxybutyric acid in a normal subject. Note the overshoot in FFA and $\beta$-hydroxybutyric acid levels occurring after $3 \mathrm{~h}$

in Fig. 6, where the ketone level was increased threefold $6 \mathrm{~h}$ after giving $1 \mathrm{~g}$ of nicotinic acid by mouth.

Ideally future antilipolytic agents should not give rise to overshoot. For longterm clinical use it would also be desirable if such agents only brought the excessive FFA mobilization back to normal, and did not reduce the FFA mobilization into the subnormal range. Further studies on physiologically occurring, strong antilipolytic agents such as insulin and prostaglandins may be of great value for developing antilipolytic treatment.

Acknowledgement. The work reviewed in this Minkowski lecture is the result of many people's work. My 
sincere thanks go to among others: Drs. J. BoBerg, U. Freyschuss, S. Fröberg, R.C. Gross, R.J. Haved, H. Micheil, E.R. Nye, L. ORö and J. Östman for pleasant collaboration, to Mrs. Kerstin CarLson for still being Mrs. Carlison and to BJörn [14], Mats [11], Pra Maria [9]

for continuous stimulation and patience with their father.

\section{References}

1. Biemman, E., B.P. Dole, and T.N. Roberts: An abnormality in nonesterified fatty acid metabolism in diabetes mellitus. Diabetes 6, 475-479 (1957).

2. BuTCHER, R.W., and C.E. BAIRD: The regulation of cyclic AMP and lipolysis in adipose tissue by hormones and other agents. Advances in experimental medicine and biology, Ed. W. L. Holmes, L.A. Carison and R. Paoletir, Vol 4, 5-23 (1969).

3. Carlson, L.A.: Inhibition of the mobilization of free fatty acids from adipose tissue. Ann. N.Y. Acad. Sci. 131, 119-142 (1965).

4. - Consequences of inhibition of normal and excessive lipid mobilization. Studies with nicotinic acid. Progr. biochem. Pharmacol. 3, 151-166 (1967).

5. - , and J. ÖsTMAN: In vitro studies on the glucose uptake and fatty acid metabolism of human adipose tissue in diabetes mellitus. Acta med. scand. 174, $215-218(1963)$.

6. - - Effect of salicylates on plasma free fatty acid in normal and diabetic subjects. Metabolism 10, 781 787 (1961)

7. - - Inhibition of the mobilization of free fatty acids from adipose tissue in diabetes. II. Effect of nicotinic acid and acetylsalicylate on blood glucose in human diabetics. Acta med. scand. 178, 71-79 (1965).

8. - - Inhibition of the mobilization of free fatty acids from adipose tissue in diabetes. I. Effect of nicotinic acid on the alloxan diabetic state in rats. Acta med. scand. 177, 631-637 (1965).

9. - - Plasma beta-hydroxybutyric acid response to nicotinic acid-induced plasma free fatty acid decrease in man. Diabetologia 2, 127-129 (1966).

10. - , and L. Orö: The effect of nicotinic acid on the plasma free fatty acids. Demonstration of a metabolic type of sympathicolysis. Acta med. scand. 172, $641-$ $645(1962)$.
11. - U. Freyschuss, J. KJeliberG, and J. Óstman: Suppression of splanchnic ketone body production in man by nicotinic acid. Diabetologia 3, 494-499 (1967).

12. EBstern, W.: Zur Therapie des Diabetes Mellitus, insbesondere über die Anwendung des salicylsauren $\mathrm{Na}$. tron bei demselben. Berl. klin. Wschr. 13, 337-341 $(1876)$.

13. Fint, M.B., and R.H. Williams: Effect of fasting, epinephrine, glucose and insulin on hepatic uptake of free fatty acids. Amer. J. Physiol. 199, 403-407 (1960).

14. Gross, R.C., and L.A. Cartson: Metabolic effects of nicotinic acid in acute insulin deficiency in the rat. Diabetes 17, 353-361. (1968).

15. Hales, C.N.: The glucose-fatty acid cycle and the aetiology of diabetes. Proc. Nutr. Soc. 25, 61-66 (1966).

16. LAURELI, S.: Plasma free fatty acids in diabetic acidosis and starvation. Scand. J. clin. Lab. Invest. $8,81-82(1956)$.

17. Östman, J.: Effect of nicotinic acid on the fatty acid metabolism of adipose tissue in alloxan diabetic rats. Metabolism 13, 675-680 (1964).

18. - Studies in vitro on fatty acid metabolism of human subcutaneous adipose tissue in diabetes mellitus. Acta med scand. 177, 639-655 (1965).

19. Pereira, J.N.: The plasma free fa.tty acid rebound induced by nicotinic acid. J. Lipid Res. 8, 239-244 (1967).

20. Porte, D., JR. : Sympathic regulation of insulin secretion. Arch. intern. Med. 123, 252-260 (1969)

21. RandLe, P.J.: Carbohydrate metabolism and lipid storage and breakdown in diabetes. Diabetologia 2, $237-247(1966)$.

22. SpItzer, J.J., and W.T. McElroy, JR.: Some hormonal effects on uptake of free fatty acids in the liver. Amer. J. Physiol. 199, 876-882 (1960).

23. WRIGHT, P.H.: The production of experimental diabetes by means of insulin antibodies. Amer. J. Med. 31, 892-900 (1961).

Lars A. Carlson

King Gustaf Vth Research Institute

Stockholm, Sweden 